\title{
The Conundrum of Treating Chronic Pain in Older Adults
}

\section{Paul Arnstein*}

Paul Arnstein, Clinical Nurse Specialist, Massachusetts General Hospital, USA

*Corresponding author: Paul Arnstein, Clinical Nurse Specialist, Massachusetts General Hospital, USA, Tel: +617-724-8517; E-mail: pmarnstein@mgh.harvard.edu

Received date: February 09, 2016; Accepted date: April 11, 2016; Published date: April 18, 2016

Copyright: @ 2016 Arnstein P. This is an open-access article distributed under the terms of the Creative Commons Attribution License, which permits unrestricted use, distribution, and reproduction in any medium, provided the original author and source are credited.

\begin{abstract}
:
Despite remarkable advances in healthcare, chronic pain afflicting millions of older adults remains poorly treated. Intense or prolonged exposure to pain creates degenerative changes throughout the nervous system, which intensifies, prolongs and spreads it. The loss of brain gray matter with persistent pain greatly outpaces that seen with normal aging and can explain the learning, memory and emotional difficulties experienced. This loss can be partially reversed with effective treatment.
\end{abstract}

Keywords: Older adults; Pain; Kidney; Anticonvulsant

\section{Introduction}

The recent release of CDC guidelines for managing chronic pain may create a challenge for those treating older adults who have been maintained on stable doses of opioids for months or years. Clinicians will need to balance concerns about the potential harms of unrelieved pain, with the potential harms of initiating or continuing opioids. According to these guidelines, opioid therapy should be tapered and stopped in patients who do not continue to sustain a $30 \%$ reduction in both pain intensity and disability. To date, no available treatment has been shown to yield these sustainable effects in older adults. Intense or prolonged exposure to pain creates degenerative changes throughout the nervous system, which intensifies, prolongs and spreads it $[1,2]$. The loss of brain gray matter with persistent pain greatly outpaces that seen with normal aging and can explain the learning, memory and emotional difficulties experienced by many with chronic pain [3-5]. Emerging research suggests this loss may be partially reversible with effective treatment [6-8].

Persistent severe pain in older adults has been linked to a loss of retirement savings and increasing frailty [9-11]. Patients with persistent severe pain are significantly more likely to attempt suicide than those without pain. In particular, pain intensity, mental defeat, functional limitations, and being perceived as a burden to others is strongly associated with suicidal ideation and attempts [12-14]. Even after controlling for life-limiting diseases, those with severe chronic pain die at a $50 \%$ higher rate (especially from cardiovascular events) over 10 years than those without pain [15]. Thus it is currently unclear what is a greater threat to the health and longevity of older adults: severe, persistent pain or the medications used to treat it. Regardless of age, patients with a substance use disorder have a 2-4 higher prevalence of overdoses than those without this risk factor, and it is unclear what percentage of these deaths are intentional versus unintentional [16]. Although most of the addiction and overdose deaths that gave rise to the attention paid to the opioid crisis occur at a younger age; older adults are also vulnerable to these problems $[17,18]$. Yet non-opioid pharmacologic therapies, particularly in older patients, and those with certain co-morbidities such as cardiovascular, renal, gastrointestinal, and liver disease also raise the risk of unintentional poisonings or death $[16,19]$.
The CDC guidelines call for opioids to be used after non-opioids and non-drug therapies have failed [16]. For older adults, opioids have until recently been considered second-line for chronic pain after acetaminophen and/or adjuvant drugs fail [20]. Acetaminophen has either not been studied, or is ineffective in treating the most common painful conditions affecting older adults [21-23]. Common adjuvant drugs (e.g. anticonvulsants, antidepressants) can require sequential trials lasting several weeks or months to achieve therapeutic doses in older adults; often hampered by adverse effects such as sedation, dizziness and impaired age-related renal function [16,24]. Unfortunately, these adjuvants work in fewer than a third of cases $[23,25]$ and should be avoided in older adults with a history of certain illnesses, past falls or fractures [26]. Nonsteroidal Anti-Inflammatory Drugs (NSAIDs) should not be used chronically unless alternatives fail to be effective; and gastroprotection is used $[20,26]$. However, a history of cardiovascular, gastrointestinal or kidney disease precludes the use of NSAIDs and proton pump inhibitor gastroprotection can be hazardous for older adults [26]. Nondrug treatments including chronic pain programs have emerged as promising therapeutic options to help older adults better function and cope despite the persistence of pain. These approaches are limited by program heterogeneity, accessibility, attrition and difficulty sustaining modest therapeutic gains [27-33]. Internet, smart phone and/or tablet computer technologies are being introduced to address barriers and enhance treatment effects with the potential to transform the way chronic pain is understood and managed by patients [34-38]. These are increasingly viable ways to engage older adults in therapy that has traditionally been difficult for them to benefit from by overcoming transportation, cost and other barriers to access in this population [39-41]. Continued development of safer, effective treatments and our system of providing pain relief to older adults is needed because continuing to ignore the harmful effects of severe persistent pain is unconscionable [42,43]. Paul Arnstein, RN, $\mathrm{PhD}, \mathrm{FAAN}$ is a Clinical Nurse Specialist for Pain Relief at Massachusetts General Hospital in Boston Massachusetts; a Mayday Pain and Society Fellow; and a contributor to the National Pain Strategy. He wishes to acknowledge the Connell Nursing Research Scholar program that has supported his investigation of Technologyassisted Pain Relief Programs for older adults. 


\section{References}

1. Woolf CJ, Salter MW (2000) Neuronal plasticity: increasing the gain in pain. Science 288: 1765-1769.

2. Aronoff GM (2016) What Do We Know About the Pathophysiology of Chronic Pain? Implications for Treatment Considerations. Med Clin North Am 100: 31-42.

3. Apkarian AV, Sosa Y, Sonty S, Levy RM, Harden RN, et al. (2004) Chronic back pain is associated with decreased prefrontal and thalamic gray matter density. J Neurosci 24: 10410-10415.

4. Kuchinad A, Schweinhardt P, Seminowicz DA, Wood PB, Chizh BA, et al. (2007) Accelerated brain gray matter loss in fibromyalgia patients: premature aging of the brain? J Neurosci 27: 4004-4007.

5. Mutso AA, Radzicki D, Baliki MN, Huang L, Banisadr G, et al. (2012) Abnormalities in hippocampal functioning with persistent pain. J Neurosci 32: 5747-5756.

6. Davis KD, Moayedi M (2013) Central mechanisms of pain revealed through functional and structural MRI. J Neuroimmune Pharmacol 8: 518-534.

7. Seminowicz DA, Wideman TH, Naso L, Hatami-Khoroushahi Z, Fallatah S, et al. (2011) Effective treatment of chronic low back pain in humans reverses abnormal brain anatomy and function. J Neurosci 31: 7540-7550.

8. Seminowicz DA, Shpaner M, Keaser ML, Krauthamer GM, Mantegna J, et al. (2013) Cognitive-behavioral therapy increases prefrontal cortex gray matter in patients with chronic pain. J Pain 14: 1573-1584.

9. Saastamoinen $P$, Laaksonen $M$, Kääriä $S M$, Lallukka T, Leino-Arjas $P$, et al. (2012) Pain and disability retirement: a prospective cohort study. Pain 153: 526-531.

10. Schofield D, Kelly S, Shrestha R, Callander E, Passey M, et al. (2012) The impact of back problems on retirement wealth. Pain 153: 203-210.

11. Wade KF, Lee DM, McBeth J, Ravindrarajah R, Gielen E, et al. (2016) Chronic widespread pain is associated with worsening frailty in European men. Age Ageing 45: 268-274.

12. Tang NK, Beckwith P, Ashworth P (2016) Mental Defeat Is Associated With Suicide Intent in Patients With Chronic Pain. Clin J Pain 32: 411-419.

13. Kowal J, Wilson KG, McWilliams LA, Péloquin K, Duong D (2012) Selfperceived burden in chronic pain: relevance, prevalence, and predictors. Pain 153: 1735-1741.

14. Van Orden KA, Wiktorsson S, Duberstein P, Berg AI, Fässberg MM, et al. (2015) Reasons for attempted suicide in later life. Am J Geriatr Psychiatry 23: 536-544.

15. Torrance N, Elliott AM, Lee AJ, Smith BH (2010) Severe chronic pain is associated with increased 10 year mortality. A cohort record linkage study. Eur J Pain 14: 380-386.

16. Dowell D, Haegerich TM, Chou R (2016) CDC Guideline for Prescribing Opioids for Chronic Pain - United States, 2016. MMWR Recomm Rep 65: 1-49.

17. West NA, Dart RC (2015) Prescription opioid exposures and adverse outcomes among older adults. Pharmacoepidemiol Drug Saf

18. Rudd RA, Aleshire N, Zibbell JE, Gladden RM (2016) Increases in Drug and Opioid Overdose Deaths - United States, 2000-2014. MMWR Morb Mortal Wkly Rep 64: 1378-1382.

19. Bronstein AC, Spyker DA, Cantilena LR Jr, Green JL, Rumack BH, et al. (2010). 2009 Annual report of the American Association of Poison Control Centers' National Poison Data System (NPDS): 27th annual report. Clinical Toxicology (Phila) 48: 979-1178.

20. American Geriatrics Society Panel on Pharmacological Management of Persistent Pain in Older Persons (2009) Pharmacological management of persistent pain in older persons. J Am Geriatr Soc 57: 1331-1346.

21. Felson D (2015) Paracetamol is ineffective for spinal pain and knee and hip osteoarthritis. Evid Based Med 20: 205.

22. Machado GC, Maher CG, Ferreira PH, Pinheiro MB, Lin CW, et al (2015) Efficacy and safety of paracetamol for spinal pain and osteoarthritis: systematic review and meta-analysis of randomised placebo controlled trials. BMJ 350: h1225.

23. Finnerup NB, Attal N, Haroutounian S, McNicol E, Baron R, et al. (2015) Pharmacotherapy for neuropathic pain in adults: a systematic review and meta-analysis. Lancet Neurol 14: 162-173.

24. Pickering G (2014) Antiepileptics for post-herpetic neuralgia in the elderly: current and future prospects. Drugs Aging 31: 653-660.

25. Gaskell H, Derry S, Moore RA (2014) Treating chronic non-cancer pain in older people--more questions than answers? Maturitas 79: 34-40.

26. By the American Geriatrics Society 2015 Beers Criteria Update Expert Panel (2015) American Geriatrics Society 2015 Updated Beers Criteria for Potentially Inappropriate Medication Use in Older Adults. J Am Geriatr Soc 63: 2227-2246.

27. Williams AC, Eccleston C, Morley S (2012) Psychological therapies for the management of chronic pain (excluding headache) in adults. Cochrane Database Syst Rev 11: CD007407.

28. Hayden JA, van Tulder MW, Malmivaara A, Koes BW (2005) Exercise therapy for treatment of non-specific low back pain. Cochrane Database Syst Rev : CD000335.

29. Fransen M, McConnell S, Harmer AR, Van der Esch M, Simic M, et al. (2015) Exercise for osteoarthritis of the knee. Cochrane Database Syst Rev 1: CD004376.

30. Fransen M, McConnell S, Hernandez-Molina G, Reichenbach S (2014) Exercise for osteoarthritis of the hip. Cochrane Database Syst Rev 4.

31. Busch AJ, Barber KA, Overend TJ, Peloso PM, Schachter CL (2007) Exercise for treating fibromyalgia syndrome. Cochrane Database Syst Rev : CD003786.

32. Lee C, Crawford C, Swann S (2014) Active Self-Care Therapies for Pain (PACT) Working Group. Multimodal, integrative therapies for the selfmanagement of chronic pain symptoms. Pain Med 15: S76-85.

33. Kamper SJ, Apeldoorn AT, Chiarotto A, Smeets RJ, Ostelo RW, et al. (2015) Multidisciplinary biopsychosocial rehabilitation for chronic low back pain: Cochrane systematic review and meta-analysis. Cochrane Database Syst Rev 9: CD000963.

34. Macea DD, Gajos K, Daglia Calil YA, Fregni F (2010) The efficacy of Web-based cognitive behavioral interventions for chronic pain: a systematic review and meta-analysis. J Pain 11: 917-929.

35. Keefe FJ, Huling DA, Coggins MJ, Keefe DF, Zachary Rosenthal M, et al. (2012) Virtual reality for persistent pain: a new direction for behavioral pain management. Pain 153: 2163-2166.

36. Naylor MR, Keefe FJ, Brigidi B, Naud S, Helzer JE (2008) Therapeutic Interactive Voice Response for chronic pain reduction and relapse prevention. Pain 134: 335-345.

37. Holzner B, Giesinger JM, Pinggera J, Zugal S, Schöpf F, et al. (2012) The Computer-based Health Evaluation Software (CHES): a software for electronic patient-reported outcome monitoring. BMC Med Inform Decis Mak 12: 126

38. Rini C, Porter LS, Somers TJ, McKee DC, DeVellis RF, et al. (2015) Automated Internet-based pain coping skills training to manage osteoarthritis pain: a randomized controlled trial. Pain 156: 837-848.

39. Rini C, Williams DA, Broderick JE, Keefe FJ (2012) Meeting them where they are: Using the Internet to deliver behavioral medicine interventions for pain. Transl Behav Med 2: 82-92.

40. Parker SJ, Jessel S, Richardson JE, Reid MC (2013) Older adults are mobile too!Identifying the barriers and facilitators to older adults' use of mHealth for pain management. BMC Geriatr 13: 43.

41. Riva S, Camerini AL, Allam A, Schulz PJ (2014) Interactive sections of an Internet-based intervention increase empowerment of chronic back pain patients: randomized controlled trial. J Med Internet Res 16: e180.

42. Barber JB, Gibson SJ (2009) Treatment of chronic non-malignant pain in the elderly: safety considerations. Drug Saf 32: 457-474.

43. Institute of Medicine (US) Committee on Advancing Pain Research, Care, and Education (2011) Relieving pain in America: A blueprint for transforming prevention, care, education, and research. Washington DC: The National Academies Press. 